\title{
Early year undergraduate researchers' reflections on the values and perceived costs of their research experience
}

\author{
Gaye D. Ceyhan ${ }^{1 *}$ (D) and John W. Tillotson ${ }^{2}$
}

\begin{abstract}
Background: Prior research reported that motivational beliefs that individuals attach to specific tasks predict continuing interest and persistence in the task. A motivational approach may be particularly useful for understanding undergraduate students' engagement with research in their first and second years in college. The current study utilizes the expectancy-value theory of achievement motivation to qualitatively explore how much and in what ways early year undergraduate researchers value their research experience and what kinds of costs they associate with it.

Results: The results revealed that intrinsic value had the highest expression in participants' motivation to engage in research. The second most expressed value type was the utility value of undergraduate research with regards to obtaining the desired outcomes, and attainment value played the least important role in participants' motivation to engage in research. Findings also indicated that some of the participants associated a cost(s) to their research experience. The highest mentioned perceived cost was opportunity cost, where participants commented on losing other valued alternatives when engaging in research. Participants commented on the time, effort, or amount of work needed to engage in research, and a few participants commented on the emotional cost associated with their research experience in terms of the fear of failure.

Conclusion: As perceived cost is the least studied in the expectancy-value framework, this study contributes to cost values within college students, particularly about early year undergraduate researchers. The findings of this study can form the basis for future work on exploring ways to increase the values and decrease the costs students experience in their undergraduate research experiences.
\end{abstract}

Keywords: Undergraduate STEM education, Undergraduate research, Motivation, Expectancy-value theory

"A motivational approach for addressing the "leaky pipeline" is particularly useful as students who have the skill and initial desire to pursue STEM careers often leave because they no longer believe they have the skills to be successful or no longer find the field interesting or personally valuable" (Linnenbrink-Garcia, Perez, Barger, \& Schwartz-Bloom, 2018 p. 182)

\footnotetext{
* Correspondence: gaye.ceyhan@boun.edu.tr

'Department of Mathematics and Science Education, Bogazici University, Istanbul, Turkey

Full list of author information is available at the end of the article
}

The term "motivation" stems from the Latin word "movere," which means "to move" (Eccles \& Wigfield, 2002, p. 110). Therefore, the study of motivation is the study of action, and in the literature, motivation is broadly described as the process (es) that affects one's participation and intention to pursue an activity (Eccles, 1994; Eccles \& Wigfield, 2002). Seymour and Hewitt (1997) pointed out the crucial role of motivational aspects in STEM retention, stating that losing interest and motivation to engage in STEM-related activities is the most common reason for students' decision to switch away from STEM majors. Although student gains and

\section{Springer Open}

(c) The Author(s). 2020 Open Access This article is licensed under a Creative Commons Attribution 4.0 International License, which permits use, sharing, adaptation, distribution and reproduction in any medium or format, as long as you give appropriate credit to the original author(s) and the source, provide a link to the Creative Commons licence, and indicate if changes were made. The images or other third party material in this article are included in the article's Creative Commons licence, unless indicated otherwise in a credit line to the material. If material is not included in the article's Creative Commons licence and your intended use is not permitted by statutory regulation or exceeds the permitted use, you will need to obtain permission directly from the copyright holder. To view a copy of this licence, visit http://creativecommons.org/licenses/by/4.0/. 
outcomes of undergraduate research (UR) experience have been well-discussed in the literature, systematic and empirical research to clarify the motivational factors, perceived drivers, and barriers of the processes of the research programs is limited (Adedokun, Bessenbacher, Parker, Kirkham, \& Burgess, 2013; Cooper et al., 2019; Gardner, Forrester, Jeffrey, Ferzli, \& Shea, 2015; Linnenbrink-Garcia et al., 2018). Mostly, evaluation and research studies regarding UR experience focus on reporting program outcomes with less emphasis have been put on exploring contextual factors (e.g., the design of the program and institutional features), sociocultural factors (e.g., socialization, mentor-student relationship), and participants' psychological factors (e.g., motivational beliefs) (Adedokun et al., 2013; Linnenbrink-Garcia et al., 2018).

Much of the literature on STEM persistence, using either concurrent or retrospective reports indicated that students in STEM majors listed interest and enjoyment as the primary reasons for their persistence in STEMrelated activities (Lopatto, 2010; McGee \& Keller, 2007; Meaders et al., 2020; Seymour \& Hewitt, 1997; Seymour, Hunter, Laursen, \& DeAntoni, 2004). For instance, students who indicate having a positive lab environment and enjoying everyday research tasks were more likely to continue their research experience (Cooper et al., 2019; Mabrouk \& Peters, 2000; Perez, Cromley, \& Kaplan, 2014) and link the perceived value of their experience to their personal and professional gains (Mabrouk \& Peters, 2000; Seymour et al., 2004; Thiry, Laursen, \& Hunter, 2011). On the other hand, students who leave their UR may not value engaging in research or may perceive high costs on staying in their UR (Cooper et al., 2019; Linnenbrink-Garcia et al., 2018). Although engaging in UR during the first year is becoming more common (Lopatto, 2010), annual results of the National Survey of Student Engagement (NSSE, 2018) revealed that students who engage in UR during their first year are $6 \%$, whereas it is $26 \%$ for seniors. It is, therefore, no surprise that studies on UR mostly explore the research experiences of students that are later in their undergraduate years or focused on the comparison of the experiences of novice and experienced undergraduate researchers (e.g., Cooper et al., 2019; Hunter et al., 2007; Hernandez, Schultz, Estrada, Woodcock, \& Chance, 2013; Maltese et al., 2017; Thiry et al., 2011). Few studies investigated the students' research experience particularly in their first and sophomore years (i.e., early year research experience) (Bowman \& Holmes, 2018; Mabrouk \& Peters, 2000; Provencher \& Kassel, 2017).

The first 2 years in college are significant periods for shaping the choices and decisions that lead to academic success and persistence in STEM (Provencher \& Kassel, 2017). Understanding student motivations during early years in college can be particularly crucial to support motivation, achievement, and persistence in STEM fields and STEM-related activities such as UR (Cromley, Perez, \& Kaplan, 2016; Mabrouk \& Peters, 2000; National Academies of Sciences, Engineering, and Medicine, 2016). UR experiences in early college years are crucial to attracting and retaining students in research-related STEM careers and strong predictors of academic success and persistence in STEM majors in the following years (Mabrouk \& Peters, 2000; Russell et al., 2007). Students who start engaging in research in their later years in college, i.e., junior or senior years, may have a more solid career plan such as going to graduate school (e.g., Bowman \& Holmes, 2018; Lopatto, 2010; Thiry et al., 2012), so studying early year research experiences may bring beneficial insights into some desired impacts of UR experience (Gardner et al., 2015; Mabrouk \& Peters, 2000). The current study utilizes the expectancy-value theory of achievement motivation to explore which values students attach to their research experience in their first and sophomore years. Moreover, engaging in a task usually comes with a cost "precisely because one choice often eliminates other options" (Eccles \& Wigfield, 2002, p. 118). Even though the expectancy-value model includes perceived cost as a crucial component, it is not widely studied in the literature (e.g., Cooper et al., 2019; Flake, Barron, Hulleman, McCoach, \& Welsh, 2015; Henry, Shorter, Charkoudian, Heemstra, \& Corwin, 2019). With this goal, this study aims to answer the following research questions:

- How much and in what ways do early year undergraduate researchers value their research experience?

- Which costs, if any, do early year undergraduate researchers attach to their research experience?

\section{Research framework}

Motivation theories focus on the relationship between the action and the beliefs, values, and goals linked to it (e.g., Eccles, 1994; Lent, Brown, \& Hackett, 1994). Although theories of motivation have derived from different psychological roots, this paper focuses on those that are most closely associated with valuerelated constructs. One of the most commonly used motivational theories that focus on academic motivation and career aspiration is the expectancy-value theory ([EVT] Eccles, 1983). EVT provides a comprehensive framework for the study of academic and career interests/choices based on expectancies, subjective task values, and career goals (Eccles, 1983; Wigfield \& Eccles, 2000). EVT integrates students' value perceptions and their beliefs about their abilities for a specific task to explain their association with career 
interests and career choices (Wigfield \& Eccles, 2000). Specifically, EVT designates the central role to students' values of the task in describing their intentions/decisions to persist in their major (Wigfield \& Cambria, 2010). According to EVT, students are more motivated to persist and achieve a task if they value the achievement of the task (e.g., reasons for finishing a task) (Wigfield \& Eccles, 2000).

Task value was described as "a quality of a task that contributes to the increasing or decreasing the probability that an individual will select it" (Eccles, 2009, p. 82). Prior research utilizing EVT suggests that task values are "the most immediate or direct predictors of academic engagement and career choices" (Wigfield \& Cambria, 2010, p. 36). According to EVT, task value is divided into four categories (Eccles \& Wigfield, 2002): (1) attainment value, (2) intrinsic value, (3) utility value, and (4) perceived cost (Eccles, 1994, 2009; Wigfield \& Eccles, 2000).

The attainment value is the importance of individuals attach to doing well on a task or how well the given task fits with the individuals' identity (Wigfield \& Eccles, 2000). Eccles and Wigfield (2002) associate attainment value to "the relevance of engaging in a task for confirming or disconfirming salient aspects of one's self-schema" (p. 119). Perez et al. (2014) provided an example to illustrate attainment value:

A student who chooses environmental biology as his major because the major is consistent with his identity as an environmentally conscious person or environmentalist. The major would be important to this student beyond its usefulness in getting an environmental science job in the future. (p. 16)

Thus, it can be said that tasks may be valued partly because of the consistency of the task with the person's identity. Therefore, participating in STEM-related activities, such as UR, may fit with the students' identity, support their connection to STEM fields, and may promote their persistence in their STEM major (LinnenbrinkGarcia et al., 2018).

The intrinsic value is the interest and enjoyment individuals gain from engaging in a specific task (Wigfield \& Eccles, 2000). Intrinsic value is similar to intrinsic motivation, which is described as "doing an activity for the inherent satisfaction of the activity itself" (Ryan \& Deci, 2000, p. 71). An example that illustrates the intrinsic value is a student who chooses a biology major because she/he has an interest in biology and enjoys biology (Eccles, 2009). Similarly, students who participate in UR may express the value of the research experience by indicating the enjoyment she/he gets from conducting research, being part of the research laboratory, or the personal interest she/he has in research.

The utility value is the usefulness of a task to individuals' current and future goals (Eccles \& Wigfield, 2002). For example, when college students "take a math class to fulfill a requirement for a science degree," they may not necessarily enjoy the math course but may be motivated by their aspiration to attain a degree in science (Wigfield \& Eccles, 2000, p. 72). Engaging in UR may fit into the short or long-term goals of the student, who may be motivated by the utility value of the research experience.

Another construct included in the expectancy-value model is the perceived cost, which is the perceived drawbacks of engaging in a task such as the effort needed for engagement, lost opportunities to engage in other tasks, and psychological or emotional costs (Eccles \& Wigfield, 2002). For example, a student may consider "is working this hard to get an A in math worth it?" or "do I do my math homework or call my friend?" (Wigfield \& Cambria, 2010, p. 40). Likewise, a student may consider the perceived cost of participating in research because UR requires spending a certain amount of time and effort in the lab, and engaging in research may preclude the student from other academic or social activities.

Literature has supported the role of task values in students' academic choices and performance in various domains and tasks (Cooper, Ashley, \& Brownell, 2017; McGrath et al., 2013; Mosyjowski, Daly, Peters, Skerlos, \& Baker, 2017; Perez et al., 2014). According to the EVT, individuals may assign one or multiple values to a task, and the degree of value they attach to the task may differ for different individuals as well (Cooper et al., 2017, 2019; Peters \& Daly, 2013; Wigfield \& Cambria, 2010). Based on the current literature, UR programs can function as a powerful contextual factor for the model of EVT (Cooper et al., 2019; Hernandez et al., 2013; Linnenbrink-Garcia et al., 2018; Robnett, Chemers, \& Zurbriggen, 2015). However, as the vast majority of the UR programs offered to juniors or seniors (though not exclusively) (NSSE, 2018), the existing literature largely explain students' task values associated with their research experience starting at the end of the sophomore or junior year (e.g., Hernandez, Woodcock, Estrada, \& Schultz, 2018; Seymour et al., 2004; Thiry et al., 2011). Increasing our understanding of early year undergraduate researchers' task values on their research experience may help us further understand their motivation to engage in research, which may be crucial for improving the benefits of the research programs.

\section{Value-related beliefs and STEM persistence}

Drawing from EVT, expectancies, and task values are direct predictors of performance, persistence, and task 
choice in various contexts (Eccles \& Wigfield, 2002). EVT has been applied to various fields and domains, including academics, sports, and arts (Wigfield \& Eccles, 2000). Mostly quantitative measures have been used to measure the expectancy, and value-related constructs (e.g., Wigfield \& Cambria, 2010), and recently qualitative studies have been conducted to investigate the association of these constructs with performance and persistence (e.g., Cooper et al., 2017; Masson, Klop, \& Osseweijer, 2016; McGrath et al., 2013). For this paper, only academic implementation of the EVT has been reviewed. Based on the current literature, task values are essential factors for achievement performance of the task and choice selection in STEM fields (e.g., McGrath et al., 2013; Perez et al., 2014; Robinson, Perez, Nuttall, Roseth, \& Linnenbrink-Garcia, 2018).

McGrath et al. (2013) used a qualitative study design to investigate how first-year engineering students perceive engineering to increase our understanding of why some students persist while some others leave the program. Their findings revealed that task values were the strongest indicators of students' decision to persist or leave with the largest Cohen's $D$ effect size on the intrinsic value and followed by the perceived cost. On the other hand, their findings related to utility value contradicted with the literature indicating a slight negative correlation with persistence (e.g., Eccles \& Wigfield, 2002; Linnenbrink-Garcia et al., 2018).

In another study, Perez et al. (2014) conducted a short-term longitudinal study with 363 diverse undergraduate students to investigate the role of science identity development processes on the motivational beliefs and intentions/decisions to persist in the STEM majors. Their study is unique because they not only explored the attainment, utility, and intrinsic values but also investigated the cost value deeply by including the three types of cost value in their research models, which are effort cost, opportunity cost, and psychological cost. Supported by the career development literature, their findings revealed that identity development procedures are mediated through students' motivational beliefs (Perez et al., 2014). The authors explained their finding by stating "students who made commitments to a STEM career after identity exploration were likely to be more motivated in their major, which in turn was related to their intentions to stay in the major" (Perez et al., 2014, p. 325). Their findings also revealed that the association between perceived cost and choice behavior is stronger than the link between perceived cost and academic performance (Eccles, 2009).

In a recent study, Appianing and Van Eck (2018) developed and validated the value-expectancy STEM Assessment Scale to measure female undergraduate students' value for and expectations regarding STEM fields and careers. Similar to the literature, the findings of the study revealed that female students with higher expectations for success and higher value perceptions are more likely to persist in a STEM major (Eccles, 2009; Perez et al., 2014; Wigfield \& Cambria, 2010). Moreover, their findings also supported the literature by finding a strong association between expectation for success and the value students attach to their STEM majors (Eccles, 2009; Eccles \& Wigfield, 2002). Although literature regarding the subjective task values and STEM persistence provide important insights, exploring the values undergraduate students attach to STEM-related experiences, such as UR, may help us further understand the motivational factors to engage in STEM-related tasks.

\section{Subjective task values students attach to undergraduate research experience}

Based on the premises of the EVT, we would suppose that the task values in STEM-related activities are crucial aspects that may be helpful to promote careers in STEM fields (Appianing \& Van Eck, 2018; Linnenbrink-Garcia et al., 2018; Perez et al., 2014; Robinson et al., 2018). For instance, Linnenbrink-Garcia et al. (2018) conducted a comparison study with 587 undergraduate students and used the EVT framework to investigate whether the UR program supports students' science motivation (perceived competence, self-efficacy, attainment, utility, and interest values) and whether these constructs predict science persistence. They have reported that greater perceived competence and values in STEM-related tasks predict students' persistence in STEM majors. Specifically, engagement in a research program significantly predicted science motivation (self-efficacy and task values) and showed significant direct and indirect impacts of task values for students' intentions to pursue a STEM research career (Linnenbrink-Garcia et al., 2018). Although this study is valuable in providing insight about the benefits of UR on improving students' science selfefficacy, task value, and their science persistence, the researchers did not include students' cost perceptions for participating in research in their model. However, the literature pointed out the importance of perceived cost in achievement, performance, and persistence (e.g., Flake et al., 2015; Henry et al., 2019; Perez et al., 2014; Wigfield \& Cambria, 2010).

Hernandez et al. (2013) conducted a longitudinal analysis with 1046 underrepresented undergraduate students from 38 universities to investigate the role of scientific self-identity, task values, and faculty interaction on the goal orientations of undergraduate STEM researchers as well as the effect of these values on the performance of the students and their persistence in STEM fields. The researchers found that increasing engagement in research experiences and enhancing science-identity 
have a strong positive influence on "growth in the task and performance-approach goals," but only task values positively impacted students' GPA (Hernandez et al., 2013, p. 18). Findings of the studies explained above are valuable to clarify the directional paths of the goals, selfefficacy, and science-identity constructs on students' research experience, yet there is a need for an in-depth exploration of undergraduate researchers' motivations to engage in research to determine how much and in what ways they value their research experience and what kinds of costs they associate with it.

\section{Methodology}

\section{Context and participants}

The participants of this study were twenty-four lowincome, academically talented STEM students from diverse backgrounds at a large research-intensive private university in the northeast USA. Data for this study were gathered from a portion of a larger NSF-funded project, the Strategic Undergraduate STEM Talent Acceleration INitiative (SUSTAIN), which aimed to provide a coherent ecosystem of academic, social, financial, and professional support systems on a diverse cohort of high achieving, low-income STEM students during their first and second year of undergraduate study (Ceyhan, Thompson, Sloane, Wiles, \& Tillotson, 2019).

Researchers recruited students through two main application and selection processes. Researchers first launched a national recruitment campaign targeting high achieving, low-income students, including underrepresented minorities, women, and students from high-need urban and rural schools from across the USA. Then, researchers targeted matriculated applicants from the pool of intended STEM majors at the university who had declared their interest in biology or chemistry departments as they are the two largest undergraduate STEM programs within the college of arts and sciences at the university, as well as serving as essential gateway majors for a wide range of STEM career professions. From a database consisting of eligible students, twenty-eight students were selected to participate in the SUSTAIN project, and the project has awarded them with $\$ 10,000$ of financial support annually for their first 2 years of academic study.

The participants of this study were twenty-four of the original twenty-eight SUSTAIN project participants. Four of the SUSTAIN project participants were removed from the current study because they did not participate in some or all of the project interventions. Two of the project participants left the university at the end of their first year. Another project participant did not participate in the project interventions including UR and switched to a non-science major at the end of his/her first year and did not participate in some or all of the data collection. One of the project participants had health issues and took a leave of absence and did not participate in some or all data collection in the sophomore year. The participants of the study were predominantly female (72\% female and $28 \%$ male), first-generation college students (88\%), and racially/ethnically diverse (13\% Asian, 8\% Black/African American, 8\% Hispanic, 21\% multiracial, 50\% White). Participants' majors were biology (33\%), biochemistry (13\%), biotechnology (4\%), forensic science (13\%), chemistry (8\%), and neuroscience (29\%).

As part of the SUSTAIN project, the participants were matched with a STEM faculty mentor from the biology or chemistry departments and spent approximately 2-3 h each week working in their mentor's laboratory during the spring semester of their first year. The participants observed and engaged in the ongoing research activities of the faculty mentor's laboratory and were encouraged to participate in weekly research group meetings. During their sophomore year, the participants engaged in guided, but increasingly independent UR with their STEM faculty mentors using the knowledge and skills acquired during their research experience in their first year and spent approximately 5-10 h each week in the laboratory. Participants were encouraged to participate in weekly research group meetings held in their mentor's lab and to attend the department colloquia featuring local and national STEM speakers to further their networking opportunities in the STEM community.

Participants had different amounts of research experience because some of them did not continue at the end of the first or second semester of their UR experience or some of them preferred to stay on campus during summer to continue their research (Ceyhan \& Tillotson, 2020). In total, eight participants had three semesters and one summer, ten participants had three semesters, four participants had two semesters, and two participants had one-semester research experience. Therefore, the vast majority of the participants (75\%) had three semesters or more research experience.

\section{Research design and measures}

This exploratory qualitative study was designed to investigate how much and in what ways early year undergraduate researchers find their research experience valuable and whether they experience a cost in engaging with research. This study aimed to contribute to the literature by addressing the motivations of undergraduate researchers to participate in research, along with giving preliminary evidence of the range of student experiences to provide a basis for generating programs to attract students in UR.

The EVT as the theoretical framework was adopted, and a qualitative approach was used for this study because qualitative research seeks to provide a rich and 
detailed understanding of a topic (Creswell \& Poth, 2016). Previous research, using quantitative measures like participant surveys, has produced valuable information about the role of task values on the outcomes of UR experiences (e.g., Hernandez et al., 2013; Robnett et al., 2015). These quantitative studies did not offer a qualitative analysis of what kind of and how much value students placed on participating in UR, and how students believed they benefited by engaging in UR. There is a lack of qualitative inquiries of UR in various STEM fields, which limits the understanding of the complexity of these experiences (Buckley, 2010). With the lack of qualitative, in-depth exploration, the relationships among the task values and the outcomes of UR experiences are not fully understood. Therefore, to answer the research questions, semi-structured individual interviews, and student-generated progress reports were used as data sources in this study. The study instruments were reviewed and approved by the institution's human subject research review board. The researcher also obtained authorization from the institution's review board to use the data sources in this study (IRB No. 19-045). Figure 1 below shows the data sources and data collection times. Also, the semesters that the participants engaged in the research were indicted in dark.

\section{Interviews}

The SUSTAIN project team developed interview protocols for each interview. The first set of interviews were conducted at the end of the first year of the SUSTAIN project participants in the Spring 2018 semester, which was developed to assess the participants' first-year research experience, as well as the mentoring provided to them and in what ways the research experience helps the development of their science identity and their socialization into the STEM community, the value of this experience and their level of satisfaction with their research experience. The second set of interviews were conducted at the end of the sophomore year of the SUSTAIN project participants in Spring 2019.
Some of the questions from the first interview remained the same to explore the support provided to the participants, the value they attach to their experience, and their overall satisfaction. Some new questions were added to attain the participants' sophomore research experience and to investigate if there is a difference between their first- and second-year research experience. Both of the interviews were conducted with all the participants. If the participant did not continue their research experience after one or two semesters, the interview questions were asked to reflect on the semesters they participated in the research. All interviews were conducted face-to-face and audio-recorded, with an average duration of $45 \mathrm{~min}$ in length. The interviews were then transcribed.

\section{Progress reports}

SUSTAIN project participants provided mid-semester and end-semester progress reports during their research experience (i.e., one mid-semester report and one endsemester report in Fall 2018 and one mid-semester report and one end-semester report in Spring 2019). The goals of the progress reports were to obtain continuous information about the progress in the participants' research experience, their roles and responsibilities, expectations and actual experiences, and the value of their experience so far. Each progress report reflected their progress within that period. For instance, for the midsemester report in Spring 2019, participants shared their experience after the end-semester report in Fall 2018 up to that time.

\section{Data analyses}

NVivo Pro 12 qualitative data analysis software program was used as the data analysis tool. Each participant was coded with their SUSTAIN-ID numbers and identified as an individual case in the NVivo program. Interviews and progress reports of each participant were uploaded to the program to be organized and analyzed. Before data analysis, the first step was data cleaning and case coding (Feng \& Behar-Horenstein, 2019). Each data

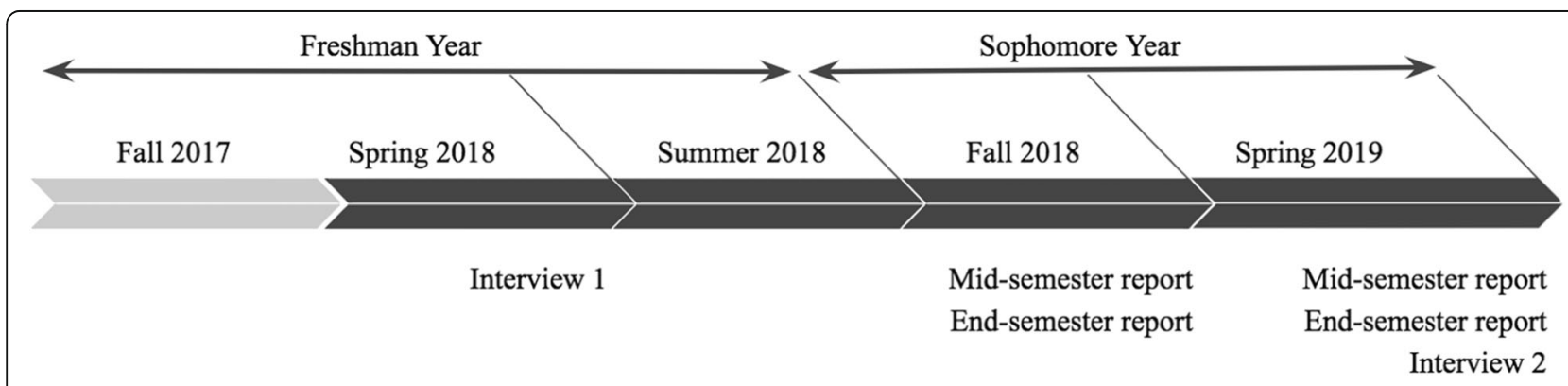

Fig. 1 Data sources and data collection times 
source was assigned to the corresponding case. For instance, each interview and progress report for the participant with SUSTAIN-ID \#1 was assigned to the case identified by \#1. After case coding, case classifications were coded regarding the participants' demographic attributes (gender, race/ethnicity, and amount of research participation).

Once the case coding and classifications were completed, the entire data set was read, reread, and coded multiple times, to ensure that all emergent codes, categories, and subcategories were identified (see the codebook in the supplementary materials). Mainly, the first author conducted the data analysis. The researcher, therefore, took multiple methodological actions to ensure the reliability of the data analysis process. A rich description of the data analysis procedure was provided to the SUSTAIN project research team to promote transferability judgments (Korstjens \& Moser, 2018). The researcher made multiple and constant comparisons within one participant's multiple data sources and between different participants' experiences to ensure vertical and horizontal analyses (Lincoln \& Guba, 1985). The vertical analysis involved focusing on one piece of data at a time and horizontal analysis included the analysis of across pieces of data. For instance, the researcher first observed and coded the intrinsic value where participants indicated their interest and enjoyment of engaging in research. The vertical internal analysis of intrinsic value was conducted by comparing all the intrinsic value codes within one participant's multiple data sources to check the internal consistency of the assigned code. The horizontal analysis of the intrinsic value, on the other hand, involved analyzing different participants' data sources, with more emphasis on the whole (Korstjens \& Moser, 2018).

The vertical and horizontal analyses were continued until the stability of the findings were obtained to promote the dependability of the analyses (Korstjens \& Moser, 2018; Lincoln \& Guba, 1985). The first and second authors discussed coding results and categories between reading episodes until reaching full agreement to assure the inter-subjectivity of the data and to facilitate confirmability of the analysis (Korstjens \& Moser, 2018; Lincoln \& Guba, 1985). Also, weekly project meetings with the SUSTAIN project research team were organized to communicate and ensure the dependability and confirmability of the codes and categories. The debriefing process with the research team meetings helped to make a rigorous external check of the data collection, analysis, and interpretation processes (Lincoln \& Guba, 1985).

The data collected through the progress reports and interviews were analyzed through deductive coding into predetermined thematic categories (Fereday \& Muir-Cochrane, 2006). Data analyses were conducted chronologically, and codebooks were developed, respectively. The predetermined concepts that were used to analyze the subjective task values deductively were (1) attainment value, (2) intrinsic value, (3) utility value, and (4) perceived cost. These predetermined concepts were based on the EVT framework and previous studies (e.g., Eccles, 2009; Eccles \& Wigfield, 2002; Wigfield \& Cambria, 2010).

In each of the data sources, the participants' comments were highlighted regarding the type of value and the cost they placed on their research experience. Following the deductive analysis, the data were also analyzed inductively to identify the codes based on emergent patterns in the data (Patton, 2002). There were differences in the emphasis participants gave to each value type. Thus, following the deductive and inductive data analysis, each participants' responses were analyzed considering the relative amount of discussion to determine the importance of each value type for the participants. For each participant, the frequency of discussion about each type of value was ranked, with one representing the most expression and three representing the least (McGrath et al., 2013; Peters \& Daly, 2013). In some cases, relative discussion of some value types was very close, whereas in other cases there were substantial differences in the amount of discussion about the value types. As also mentioned in the literature, the difference between the ranks was not equal, and "value types with the same rank across multiple participants indicate the order of rank, but rank order does not mean that the participants placed the same weight on that value type" (Peters \& Daly, 2013, p. 252).

\section{Results}

The results from the interviews and progress reports were explained to identify how valuable students find their research experience and whether they associate a cost to participate in research regarding the expectancy-value model. While presenting the results, at first, each value type was discussed separately to provide an in-depth explanation of what ways participants value their research experience. The EVT framework was used in the analysis of values, but also the categories of the types of values were subdivided according to the inductive analysis. Some preliminary trends were discovered based on the level of emphasis given to each value type, which will be discussed in the comparison of the values section of the results. Then, findings related to the participants' comments on the costs of participating in UR were presented at the end of the "Results" section. Pseudonyms were assigned to the quotes by numbering participants from one to twentyfour to indicate whom the quote belongs to. 


\section{Motivating values for undergraduate researchers}

This section focused on the first research question: How much and in what ways do early year undergraduate researchers value UR? Data showed that participants engage in research for a variety of reasons. Regarding both deductive and inductive analysis, attainment, interest, and utility value participants attach to their research experience was presented, subcategories were explained by providing participants' comments. Finally, the weight of each value type for each participant was discussed.

\section{Attainment value}

As the attainment value is related to the self-image of individuals, participants' comments relating their selfimage to the researcher and their perceptions of self as a scientist were considered in this value type. However, attainment value was not mentioned by nearly half of the participants. Only half of the participants commented on the alignment of research with their sense of self, personal importance of engaging in research, or the contribution of research on their science identity. Participants who commented on the attainment value of research expressed (1) how the research topic matches their interest area, (2) being a researcher fits their identity, (3) personal importance of engaging in research early in their undergraduate study (see Table 1).

Some of the participants with different amounts of research experience did not associate research with their sense of self. Even though these participants expressed the value of having research experience during their first and sophomore years, they also indicated that research does not match with their self-schema. Participant 17 who had three semesters of research experience indicated that she likes the experience as an undergraduate researcher but also revealed that it is not for her and it does not fit with what she wants to do.
Lab work, just not for everybody. I want to be in the field. I want to be at the crime. I do not want to be in the lab testing the stuff. I want to be the one figuring everything out. Being in the lab made me realize I like it, I enjoy it. I know I am learning, but it is not something I want to continue to do.

\section{Intrinsic value}

Except for one participant, all others expressed evidence of interest and enjoyment of the UR experience. The vast majority of the participants revealed that their motivation to engage in research was influenced by their interest in the research project they engaged in or the research process in general (see Table 2). Participants expressed the intrinsic value they associate with their research experience with (1) their joy of everyday tasks in the laboratory, (2) learning more about science and how science works, (3) positive lab environment, and how lab members interact with each other. For instance, participant 9 stated that "the actual work in the lab and writing it down in the notebook and testing everything and when it's successful, I definitely like it more than I thought I would." Participant 6 also stated, "if it was not enjoyable, I would not have been able to delve as deeply into the research as I have wanted. I think I would have kind of pushed it away instead of accepting it." As seen in Table 2, some of the participants expressed their interest in and enjoyment of the positive relationships in the research laboratory.

A few participants indicated that they do not find research interesting, exciting, or enjoyable. Some of these participants expressed that their disinterest in research did not influence their interest in the field, and participant 17 stated, "I am not a fan of being in the lab. If I did not have that experience, I would probably still be in chemistry." However, participant 11 who had one-

Table 1 Attainment value definition, subcategories, and examples of participants' statements

\begin{tabular}{|c|c|c|c|}
\hline Category & Definition & Subcategories & Sample participant statements \\
\hline \multirow[t]{3}{*}{$\begin{array}{l}\text { Attainment } \\
\text { value }\end{array}$} & $\begin{array}{l}\text { Participants indicated that engaging in } \\
\text { research is important for them and fits } \\
\text { their identity }\end{array}$ & $\begin{array}{l}\text { Alignment with the } \\
\text { sense of self }\end{array}$ & $\begin{array}{l}\text { Participant 11: We are working on women's infertility with mice. } \\
\text { And since I am trying to be a medical doctor, I think it is the } \\
\text { perfect fit for me. I am learning a lot even though I do not know } \\
\text { half of the stuff they are talking about right now because it is super } \\
\text { advanced. But just seeing how everything works and trying to } \\
\text { understand, reading the research articles so I could get a better } \\
\text { understanding of what is happening so that in the next couple of } \\
\text { years I am going to understand too. }\end{array}$ \\
\hline & & $\begin{array}{l}\text { The personal } \\
\text { importance of } \\
\text { engaging in research }\end{array}$ & $\begin{array}{l}\text { Participant 19: Not many freshmen receive the opportunity to join } \\
\text { a lab, and I would forever be thankful because it has taught me } \\
\text { things I thought I would never learn in my life. I now know the } \\
\text { value of working in a highly credited neurological research lab and } \\
\text { to be mentored by a highly knowledgeable scientist. }\end{array}$ \\
\hline & & $\begin{array}{l}\text { Recognition of self as } \\
\text { a scientist }\end{array}$ & $\begin{array}{l}\text { Participant 10: Being a scientist is important for me. I think I have } \\
\text { become more confident in myself as a STEM student, and myself in } \\
\text { all my classes. It is just added to my confidence as a premed } \\
\text { student, and as a scientist, and I just feel more comfortable tackling } \\
\text { a problem than I would have before. }\end{array}$ \\
\hline
\end{tabular}


Table 2 Intrinsic value definition and examples of participants' statements

\begin{tabular}{|c|c|c|c|}
\hline Category & Definition & Subcategories & Sample participant statements \\
\hline \multirow[t]{4}{*}{$\begin{array}{l}\text { Intrinsic } \\
\text { value }\end{array}$} & \multirow[t]{4}{*}{$\begin{array}{l}\text { Participants indicated their } \\
\text { interest and enjoyment of } \\
\text { engaging in research }\end{array}$} & \multirow[t]{2}{*}{$\begin{array}{l}\text { Finding research and/or research } \\
\text { process interesting, exciting, and } \\
\text { enjoyable }\end{array}$} & $\begin{array}{l}\text { Participant 9: Research is pretty different from what we do in class, } \\
\text { so I found that really interesting. It is not just memorizing things, } \\
\text { it is actually trying new things and coming up with your own } \\
\text { ideas, which I thought was really cool. }\end{array}$ \\
\hline & & & $\begin{array}{l}\text { Participant 5: Once you see your data and once you see the } \\
\text { results and it is something that you expect, that is just that surreal } \\
\text { feeling that you are actually doing something right. It is important } \\
\text { in that you are actually trying to make a difference somehow } \\
\text { because as humans, we all make a difference whether we like it or } \\
\text { not. We all thrive to do that. But it gives you that surreal feeling of } \\
\text { saying, "Hey, I am involved in research." }\end{array}$ \\
\hline & & \multirow[t]{2}{*}{$\begin{array}{l}\text { Finding the relationships in the } \\
\text { laboratory interesting and } \\
\text { enjoyable }\end{array}$} & $\begin{array}{l}\text { Participant 20: I think I learned there are a lot of different positions } \\
\text { in labs with the graduate students and undergraduates. They all } \\
\text { work together though, and they are all really good at delegating } \\
\text { things. I think that was really interesting. But they all have a really } \\
\text { good relationship with everyone, and especially they took me into } \\
\text { the lab and showed me how to do everything, so I think that is it } \\
\text { in terms of relationships even though I am an undergrad student, } \\
\text { they are very respectful. }\end{array}$ \\
\hline & & & $\begin{array}{l}\text { Participant 1: The people whom I work with have made it more } \\
\text { enjoyable. If I did not talk to the grad students as much as I did, if } \\
\text { I did not have my weekly meetings with my professor, I do not } \\
\text { think I would have liked it as much as I do. I figure it would have } \\
\text { made it much more difficult and not as nice to go to every day. }\end{array}$ \\
\hline
\end{tabular}

semester research experience stated that she did not like the research experience and reflected a disinterest in continuing in the STEM field, stating:

I did not even like it. I do not really like being in the lab or research. So it kind of taught me a lot. It showed me what my life really would entail in the future if I was to continue to pursue biology or chemistry or anything in the STEM field. So it gave me great insight.

\section{Utility value}

Participants differed in their explanation of the utility of their research experience (see Table 3). For the majority of the participants, the utility of engaging in UR was (1) increasing their knowledge and skills about the discipline and feeling more well-rounded, (2) learning skills and techniques, (3) shaping the career goals, (4) building professional relationships with the senior members in the laboratory and with other researchers they interact with through their research experience, (5) providing new STEM-related opportunities, and (6) being helpful with their STEM courses as either the research topic is relevant to some of their STEM courses or the techniques or terminologies they learned in the laboratory help them better understand their STEM courses. Participant 3 mentioned how the skills she learned throughout this experience helped her academic, personal, and professional development, stating:

This experience has been beneficial in allowing me to use the skills I learned in labs in order to develop my own research questions as well as to conduct research. I have improved my critical thinking skills as well as my ability to collaborate and function as a team.

Only a few participants commented on the utility of engaging in research on their STEM courses. Some of the participants indicated that research conducted in their laboratory is not related to their STEM courses. Participant 1 stated that:

The research was very specific concepts and it did not help with the general concepts of my classes. I feel like the classes I struggled the most with, like ecology and evolution, it is not related to my lab, so it does not really have a correlation.

For some of the participants, research experience was useful in building professional relationships early in their college years and was useful in providing new opportunities for them. Five participants received a grant from the Undergraduate Research and Creative Engagement Scholarship program at the university, two participants received a scholarship to attend a summer research program in Austria, one participant received a position at the university undergraduate research program over the summer, one participant received an award at the university, and one participant received an internship with a neurosurgeon at Upstate Medical University.

A few participants revealed that they do not have a clear career plan yet, whereas the majority of the participants commented on the utility of their research experience as helping them to clarify their career goals and intentions. For some participants, research experience changed, enhanced, or confirmed their career goals and they consider a research-related career by stating "I 
Table 3 Utility value definition, subcategories, and examples of participants' statements

\begin{tabular}{|c|c|c|c|}
\hline Category & Definition & Subcategories & Sample participant statements \\
\hline \multirow[t]{5}{*}{$\begin{array}{l}\text { Utility } \\
\text { value }\end{array}$} & $\begin{array}{l}\text { Participants indicated the advantages and usefulness } \\
\text { of having research experience in their undergraduate } \\
\text { education }\end{array}$ & $\begin{array}{l}\text { Feeling more } \\
\text { well-rounded }\end{array}$ & $\begin{array}{l}\text { Participant 4: I feel like I have learned a lot from being in a } \\
\text { lab, things that I could not have really learned, I guess, on my } \\
\text { own and as quickly because, as a sophomore, I feel like it is } \\
\text { kind of rare for people to have been in a lab since their } \\
\text { freshman year. I just feel like it has benefitted me in so many } \\
\text { ways. }\end{array}$ \\
\hline & & $\begin{array}{l}\text { Helped clarify } \\
\text { career goals }\end{array}$ & $\begin{array}{l}\text { Participant 17: The experience has broadened my horizons } \\
\text { and has given me a better idea of what I want to do in the } \\
\text { future. }\end{array}$ \\
\hline & & $\begin{array}{l}\text { Helped build } \\
\text { professional } \\
\text { relationships }\end{array}$ & $\begin{array}{l}\text { Participant 12: I got to meet new people and people that are } \\
\text { in a higher ranking in the field that I am in. Building a } \\
\text { relationship with Professor T. also helped, not only because } \\
\text { she was my research mentor, but because she was my } \\
\text { professor as well. So when your professor knows who you } \\
\text { are, it kind of helps because it is a familiar face. }\end{array}$ \\
\hline & & $\begin{array}{l}\text { Provided new } \\
\text { opportunities }\end{array}$ & $\begin{array}{l}\text { Participant 2: Due to my research experience, I was fortunate } \\
\text { enough to present my research at the } 2018 \text { Meredith } \\
\text { Symposium. In addition, my research led me to be the } \\
\text { Goldwater Nominee for the } 2019 \text { Goldwater Scholarship. } \\
\text { Also, I will be presenting this research at two poster sessions } \\
\text { in the spring. All of these exciting benefits of research help } \\
\text { to cultivate my growth as a chemist, a student, and a } \\
\text { researcher. }\end{array}$ \\
\hline & & $\begin{array}{l}\text { Helped with the } \\
\text { STEM courses }\end{array}$ & $\begin{array}{l}\text { Participant 22: Being in the lab also helped me with my } \\
\text { classes. What I was learning in the lab also coincided with } \\
\text { what I was learning in my classes, so that helped me } \\
\text { understand my classes better. }\end{array}$ \\
\hline
\end{tabular}

definitely want to pursue research now, and I think my lab has been a huge part of that decision", while for others, research experience clarified their career goals, helping them discover that they do not want a researchrelated career. Participant 21 expressed how his research experience helped him shape his career intentions.

I think it is useful in starting to direct what I want to do in the future because it narrows down all the opportunities that I want to do. I do not want to be a researcher anymore, and I want to look more towards more industry-related work and private work and not just work for academia.

\section{Comparison of value types}

Although participants were not asked to rate the value types, participants gave a different amount of emphasis on the value types. The relative amount of participants' discussion of each value type was determined by ranking the frequency of comments about each type of value, with the darkness of the color indicating the most expression, and "-" representing participants did not comment on the value type (i.e., not applicable). This ranking was based on the emphasis participants placed and the presence (or absence) of the values of each participants' explanation of their motivation to engage in UR. Relative discussion of some value types was very close for some participants, while it was disparate for some other participants. The trend of each participants' value expression was given in Table 4.

According to the analysis, the intrinsic value was the primary motivation for the participants' engagement with their research experience both in their first and sophomore years (see Table 4). For the participants' first year, the vast majority of the participants expressed the intrinsic value of their research experience. A few participants mentioned the utility value and only two participants commented on the attainment value of their research experience. Nearly half of the participants did not comment on the attainment value for their sophomore research experience, whereas only one participant did not comment on intrinsic value and all of the participants commented on the utility value of their experience.

For most of the participants in their sophomore year, the intrinsic value was the most emphasized, revealing that participants found their research experience interesting, exciting, or enjoyable. The second most mentioned value type was the utility value indicating that participants found their experience useful. Attainment was the lowest commented value type implying participants did not comment on the personal importance of research or how being a researcher fits with their identity. Furthermore, as can be seen in Table 4, even though participants' discussion on each value type revealed an increase in their sophomore year, there was a substantial 
Table 4 Weight given to types of values associated with the research experience

\begin{tabular}{|c|c|c|c|c|c|c|c|}
\hline \multirow[b]{2}{*}{$\begin{array}{l}\text { Amount of research } \\
\text { experience }\end{array}$} & \multirow[b]{2}{*}{ Participants } & \multicolumn{3}{|c|}{ First year } & \multicolumn{3}{|c|}{ Second year } \\
\hline & & $\begin{array}{l}\text { Attainment } \\
\text { value }\end{array}$ & $\begin{array}{l}\text { Intrinsic } \\
\text { value }\end{array}$ & $\begin{array}{l}\text { Utility } \\
\text { value }\end{array}$ & $\begin{array}{l}\text { Attainment } \\
\text { value }\end{array}$ & $\begin{array}{l}\text { Intrinsic } \\
\text { value }\end{array}$ & $\begin{array}{l}\text { Utility } \\
\text { value }\end{array}$ \\
\hline \multirow{8}{*}{$\begin{array}{l}\text { Three semesters and } \\
\text { one summer }\end{array}$} & $\mathrm{P} 1$ & 1 & - & - & 4 & 5 & 6 \\
\hline & $\mathrm{P} 2$ & - & 2 & - & 2 & 7 & 6 \\
\hline & P3 & - & 4 & - & 3 & 6 & 4 \\
\hline & $\mathrm{P} 4$ & - & 4 & 1 & 2 & 7 & 5 \\
\hline & P5 & - & 1 & - & 3 & 3 & 3 \\
\hline & P6 & 1 & 3 & 1 & - & 6 & 7 \\
\hline & P7 & - & 2 & - & - & 5 & 6 \\
\hline & P8 & - & 1 & 2 & - & 3 & 8 \\
\hline \multirow[t]{10}{*}{ Three semesters } & P9 & - & 1 & - & 1 & 8 & 2 \\
\hline & P10 & - & 2 & - & 3 & 9 & 7 \\
\hline & $\mathrm{P} 11$ & - & 3 & 1 & 2 & 6 & 2 \\
\hline & P12 & - & 3 & - & 1 & 11 & 3 \\
\hline & $\mathrm{P} 13$ & - & 1 & - & 1 & 3 & 4 \\
\hline & P14 & - & 2 & - & 3 & 8 & 3 \\
\hline & P15 & - & 2 & - & - & 3 & 1 \\
\hline & P16 & - & 2 & - & - & 9 & 3 \\
\hline & P17 & - & 1 & - & - & 5 & 3 \\
\hline & P18 & - & - & 2 & - & 4 & 5 \\
\hline \multirow[t]{4}{*}{ Two semesters } & P19 & - & 1 & 1 & 1 & 1 & 4 \\
\hline & $\mathrm{P} 20$ & - & 3 & - & 2 & 6 & 3 \\
\hline & $\mathrm{P} 21$ & - & 2 & 1 & - & 4 & 3 \\
\hline & $\mathrm{P} 22$ & - & 1 & - & - & 2 & 1 \\
\hline \multirow[t]{2}{*}{ One semester } & $\mathrm{P} 23$ & - & 1 & - & - & 2 & 1 \\
\hline & $\mathrm{P} 24$ & - & - & - & - & - & 1 \\
\hline
\end{tabular}

Note: Amount of discussion is indicated with the darkness of the color, the darkest one indicates the highest amount of discussion, and "-" represents not mentioned, where participants did not comment on the value type

rise in the amount of discussion on the utility value of their research experience. This finding fits well with the conceptualization of the extrinsic quality of utility values, which makes them more easily subject to change (Wigifield \& Cambria, 2010). This finding fits well with the literature on utility value interventions, which indicate that utility values encourage active engagement and promote the feeling of belonging (Linnenbrink-Garcia et al., 2018).

\section{Costs of engaging in undergraduate research}

This section focuses on the second research question: Which costs, if any, do early year undergraduate researchers attach to their research experience? Data from individual interviews and progress reports showed that some participants expressed the costs they associated with their research experience. Based on the deductive and inductive analysis, types of costs participants associate with their research experience were grouped in effort cost (i.e., costs associated with the effort needed to engage in research), psychological or emotional cost (i.e., participants' concerns and/or emotional consequences of failure), and opportunity cost (i.e., loss of valued alternatives) (see Table 5).

\section{Effort cost}

Some of the participants commented on the time, effort, or amount of work needed to engage in research (see Table 5). These participants described the stereotype image of the research process and the researcher in their minds. Participant 8 explained how her perception of conducting research and the amount of effort scientists put forth in research changed throughout her research experience.

I did not know what it takes to do research before I came here. I did not know that people spend their entire lives doing this kind of stuff. For me, when I 
Table 5 Definitions of the perceived costs, subcategories, and examples of participants' statements

\begin{tabular}{|c|c|c|c|c|}
\hline Category & Definition & Subcategories & Definitions & Sample participant statements \\
\hline \multirow[t]{3}{*}{$\begin{array}{l}\text { Perceived } \\
\text { cost }\end{array}$} & $\begin{array}{l}\text { Participants indicated } \\
\text { sacrifices involved in } \\
\text { engaging in undergraduate } \\
\text { research }\end{array}$ & Effort cost & $\begin{array}{l}\text { Participants indicated costs } \\
\text { associated with the effort } \\
\text { needed to engage in research }\end{array}$ & $\begin{array}{l}\text { Participant 8: I do not think I would be able to do a } \\
\text { Ph.D. program and do research day after day on the } \\
\text { same project and everything because it is just so } \\
\text { microscopic that sometimes I have a hard time } \\
\text { connecting it to the real world and seeing that impact } \\
\text { on the real world. I want to do things that will have an } \\
\text { impact on the real world, but I think the projects that I } \\
\text { would do in a research lab are going to take years to } \\
\text { do that. }\end{array}$ \\
\hline & & $\begin{array}{l}\text { Psychological/ } \\
\text { emotional cost }\end{array}$ & $\begin{array}{l}\text { Participants indicated their } \\
\text { concerns and/or emotional } \\
\text { consequences of failure }\end{array}$ & $\begin{array}{l}\text { Participant 15: Everything that is done is interesting to } \\
\text { me. But doing it myself, I find it very boring and not } \\
\text { something that I would like. I guess I do not have the } \\
\text { brain capacity to do because I feel kind of dumb in my } \\
\text { lab. And I feel like I would not know what to look for } \\
\text { and what things to research in that kind of context. }\end{array}$ \\
\hline & & $\begin{array}{l}\text { Opportunity } \\
\text { cost }\end{array}$ & $\begin{array}{l}\text { Participants indicated a loss of } \\
\text { valued alternatives }\end{array}$ & $\begin{array}{l}\text { Participant 11: I think it was valuable for my personal } \\
\text { growth and valuable for my academic growth. It } \\
\text { definitely came at a cost and I did not have a lot of } \\
\text { time to do other things that I may have wanted to do } \\
\text { on campus, other things that require a time } \\
\text { commitment because I had to commit a certain } \\
\text { amount of time. }\end{array}$ \\
\hline
\end{tabular}

thought about research, it was like a bigger impact, and you are discovering something huge, and your name is going to be on the papers, and your picture is going to be on the papers. It was kind of like discovering the cure for cancer kind of picture that I had. And I was like, "Oh, yeah, if I do one year of research or something like this-- if I spend enough time on this problem, then I can gain success and everything," and I do not think it was realistic. But after working through it, I think you need a much more practical view on it to do it because your experiments are going to fail hundreds if not thousands of times. And if you just give up after the first ten times, then you are not going to be able to go on and do the next step and the next step and the next step. And there are so many things that you have to do. And even after that, you are not guaranteed that you are going to get success, and you are going to get the results you want. So, having the patience to do research is-- I think I learned you need a lot of patience to do it.

Even though the SUSTAIN project provided financial support to project participants, some participants still worked in various jobs to meet their financial needs as a college student. A few participants commented on the difficulty of the time commitment to engage in research while trying to balance with their jobs and classes. Participant 4 stated that:

I need the money more this semester because of the things that I have going on. Working 12 hours in a lab does not seem that bad until you are actually having to schedule around your other classes and then two jobs. It gets difficult. But it is like you have to make time for it. Ultimately, I feel like it is benefitting me because I am getting something out of it. So, it is not like I am just going to the lab for no reason and giving up time to work. So, it is worth it, I feel.

\section{Psychological or emotional cost}

A few participants commented on the emotional cost associated with their research experience in terms of the fear of failure (see Table 5). Participant 24 who had one semester of research experience expressed the burden of not knowing what to do or how to do it in the research laboratory:

In the little research that I did, I was exposed to creating gels that they would use for Western Blotting, which I found very cool. But that is an entire process on its own that just drained me a lot. Because it is like how do I do this? I have never been taught this. And being taught again and again makes you feel almost pathetic because it is so you do not get it the first time and then you want to keep doing it, but you just keep failing. It was hectic for me.

\section{Opportunity cost}

The highest mentioned perceived costs among the participants were opportunity cost, where participants commented on losing other valued alternatives when engaging in research (see Table 5). Particularly, participants who had two semesters or less research experience commented the most on the opportunity cost of 
engaging in research. Participant 23 who had one semester of research experience stated, "I should have invested my time elsewhere rather than there. But it served as an eyeopener for the most part, so I appreciate that." Participant 21 who had two semesters of research experience stated that not devoting time to research let him dedicate his time to broaden his academic background in other ways.

Since I am no longer a part of a lab and do not seek to be, I have been spending the semester developing my professional brand and worked on my resume, applied to internships, and focused on what future profession I want to pursue.

Some of the participants who had three semesters or more research experience, on the other hand, stated that they do not see research experience as causing them to forgo engaging in other valued tasks by stating "I never thought that it was a waste of my time or I could be doing something better" or "I do not feel like I miss other opportunities by going to the lab. I feel like I am learning more by going to the lab." Participant 6 expressed the importance of time management and organizational skills to balance the academic and social life.

I am still involved in everything else that I want to be involved in. I just learned how to cut back in some areas and give more time to research if I am doing my experiment. But I also know, if I am not doing my experiment, there are other things in the lab that I could be doing that do not require as much time, and I can still balance everything. So I think as long as you have good organizational skills, good time management skills, you can have it all.

\section{Comparison of costs}

Similar to the comparison of the value types, the relative amount of participants' discussion of each cost type was determined by ranking the frequency of comments about each type of cost, with the darkness of the color indicating the most expression, and "-" representing participants did not comment on the cost (i.e., not applicable). The trend of each participants' cost expression was given in Table 6.

According to the analysis of the interviews and progress reports, not all participants associated a cost to their research experience, or some participants associated more than one cost. Only two participants associated a cost to their research experience in their first year. All the participants who had two semesters or less research experience emphasized at least one type of cost in their sophomore years. As can be seen in Table 6, the change from the first year to sophomore year reveals the emergence of costs about engaging in research for the participants. As Battle and Wigfield (2003) indicated "costs are related to external consequences," (p. 70) it can be said that participants did not count the costs until their second year of college when they start facing the challenges of being a STEM student (Henry et al., 2019). While sophomores are increasing their socialization into their major, beginning to think about graduate school, and learning the skills needed for success in their chosen field (Schreiner \& Tobolowsky, 2018), this may also be the time when they start considering or realizing the costs associated with the STEMrelated tasks they engage in.

\section{Discussion}

Prior research reported that motivational beliefs that individuals attach to specific tasks predict continuing motivation and persistence in the task (Eccles \& Wigfield, 2002; Linnenbrink-Garcia et al., 2018; Wigfield \& Eccles, 2000). Early year undergraduate researchers' motivation to engage in research can be explained as a function of their expected value of research participation and the costs they associated with it. Framed in the expectancyvalue model, this research explored how much and in what ways early year undergraduate researchers value their research experience and which costs they associate with engaging in research. The findings of this study revealed preliminary evidence of student experiences regarding the value and the cost they attach to their UR experience.

\section{Values undergraduate researchers attach to their research experience}

The results of this study showed that intrinsic value had the highest expression in participants' motivation to engage in research. This finding aligns with the literature on the significance of interest in motivation, engagement, persistence, and academic success in various contexts (Perez et al., 2014; Robinson et al., 2018; Torsney, Lombardi, \& Ponnock, 2019). When individuals engage in tasks that are intrinsically valued, there are significant psychological, cognitive, and behavioral consequences (Wigfield \& Eccles, 2000). As the participants of this study were in their early college years, their interest in undergraduate research may play a crucial role in their motivation to continue in research-related pathways (Bowman \& Holmes, 2018). However, as in the findings of this study, the opposite may be the case: when individuals do not intrinsically value the task, there may be various consequences.

In this study, some of the participants expressed their disinterest in research and some of them reflected their disinterest in continuing in the STEM field whereas 
Table 6 Weight given to types of costs associated with the research experience

\begin{tabular}{|c|c|c|c|c|c|c|c|}
\hline \multirow[b]{2}{*}{$\begin{array}{l}\text { Amount of research } \\
\text { experience }\end{array}$} & \multirow[b]{2}{*}{ Participants } & \multicolumn{3}{|c|}{ First year } & \multicolumn{3}{|c|}{ Second year } \\
\hline & & $\begin{array}{l}\text { Effort } \\
\text { cost }\end{array}$ & $\begin{array}{l}\text { Psyc. or } \\
\text { emotional } \\
\text { cost }\end{array}$ & $\begin{array}{l}\text { Opportunity } \\
\text { cost }\end{array}$ & $\begin{array}{l}\text { Effort } \\
\text { cost }\end{array}$ & $\begin{array}{l}\text { Psyc. or } \\
\text { emotional } \\
\text { cost }\end{array}$ & $\begin{array}{l}\text { Opportunity } \\
\text { cost }\end{array}$ \\
\hline \multirow{8}{*}{$\begin{array}{l}\text { Three semesters } \\
\text { and one summer }\end{array}$} & P1 & 1 & - & - & - & - & - \\
\hline & $\mathrm{P} 2$ & - & - & - & - & - & - \\
\hline & P3 & - & - & - & - & - & - \\
\hline & P4 & - & - & - & 1 & - & 1 \\
\hline & P5 & - & - & - & - & - & - \\
\hline & P6 & - & - & - & - & - & - \\
\hline & P7 & - & - & - & - & - & - \\
\hline & P8 & - & - & - & 2 & - & - \\
\hline \multirow{10}{*}{ Three semesters } & P9 & - & - & - & - & - & - \\
\hline & P10 & - & - & - & - & - & - \\
\hline & P11 & - & - & - & - & 1 & - \\
\hline & $\mathrm{P} 12$ & - & - & - & 1 & - & 1 \\
\hline & P13 & - & - & - & - & - & - \\
\hline & P14 & - & - & - & - & - & - \\
\hline & P15 & - & - & 1 & - & 2 & 2 \\
\hline & P16 & - & - & - & 1 & - & - \\
\hline & P17 & - & - & - & - & - & - \\
\hline & P18 & - & - & - & - & - & - \\
\hline \multirow[t]{4}{*}{ Two semesters } & P19 & - & - & - & - & - & 1 \\
\hline & $\mathrm{P} 20$ & - & - & - & - & - & 1 \\
\hline & $\mathrm{P} 21$ & - & - & - & 1 & 2 & 1 \\
\hline & $\mathrm{P} 22$ & - & - & - & 1 & 2 & 2 \\
\hline \multirow[t]{2}{*}{ One semester } & $\mathrm{P} 23$ & - & - & - & 2 & 1 & 1 \\
\hline & $\mathrm{P} 24$ & 1 & - & - & 2 & 2 & 2 \\
\hline
\end{tabular}

Note. Amount of discussion is indicated with the darkness of the color, the darkest one indicates the highest amount of discussion, and "-" represents not mentioned, where participants did not comment on the cost type

others indicated their research experience did not influence their interest in the STEM discipline. This finding is particularly significant, and future research is necessary to explore the depth and the nature of intrinsic motivations of undergraduate researchers to engage in research. UR programs should bear this fact in mind and aim at developing students' nascent STEM motivation. Also, future research is necessary to focus on understanding which features of the research experience students find valuable, in which aspects they experience more cost, and how they associate the research experience with their overall interest in STEM helps us to better respond to their needs and present other STEMrelated activities. Everyone in the STEM field does not have to enjoy conducting research. Being a researcher is not the only career option in the STEM field. It is one of many career options. Institutions should provide potential pathways to students, especially in their early years in college to help them clarify their career intentions and increase their persistence in the STEM fields.
One of the female participants expressed the encouragement she was feeling about being a woman in STEM because her mentor was a role model for her. She stated that "she is extremely encouraging and gives me a glimpse into what it is like to be a successful woman in STEM." Moreover, Kuh (2008) stated that students from underrepresented groups, including women, African Americans, and Hispanics, usually come to college with a limited understanding of science and science career options. UR provides them an environment to work closely with scientists and interact with their senior partners in the field. Therefore, students from underrepresented groups benefit from UR experience (Thiry et al., 2011) and may intrinsically motivate them to engage in research. Future research should explore differences among individuals with different demographics to better respond to their needs.

Among the participants, the second most expressed value type was the utility value of UR with regards to 
obtaining the desired outcomes (Wigfield \& Eccles, 2000). All of the participants commented on the utility of UR, but they differed in their explanation of the utility of their UR experience. Participants emphasized the utility of UR in terms of increasing their knowledge and skills about the STEM discipline, clarifying their career goals, providing new opportunities, and helping with their STEM courses. The variety of the usefulness of UR may be that the experience of early year research created different benefits, opportunities, and paths for the participants. UR programs may develop utility value interventions to better communicate and enhance the utility of UR for undergraduate researchers. Utility value interventions were found to be particularly of use to those who may normally feel alienated from STEM fields and to have a significant impact on course performance and persistence in a STEM discipline (Canning et al., 2018). UR may be a fruitful context for utility value interventions. Future research may be designed to particularly focus on the utility value of UR for early year undergraduate students to communicate personal relevance and usefulness of conducting research.

UR experience provides a "scientist-in-training" environment for students, and it may promote students' science identity (Thiry et al., 2011, p. 773). Higher science identity is theorized to be important both because it facilitates an individual's attainment and provides them with a sense of need satisfaction from engaging in an activity at which they feel effective (Chemers, Zurbriggen, Syed, Goza, \& Bearman, 2011). When considering the value of the UR experience, attainment value, which is related to the personal importance of the task or a reflection of how well the task fits with one's self-identity, played the least important role in participants' motivation to engage in research. Although identities are formed through practice (Wenger, 1998), fitting the task with identity takes time (Carlone \& Johnson, 2007; Eccles \& Wigfield, 2002).

In this study, nearly half of the participants commented on the personal importance or how well research fit with their identity, and there is no pattern according to their demographics or the amount of their research experience. It may be because recognition of self as a scientist may require a deeper engagement with the activity (Carlone \& Johnson, 2007). It may also be that attainment value is sparse when science identity is low during the early years in college. The findings of this study suggest that UR programs and student support interventions should emphasize students' science identity development throughout their research experience, which may promote the attainment value of UR and increased motivation to continue engaging in research. More research is necessary to explore the identity formation of early year undergraduate students and the role of UR experience on the science identity of students.

\section{Costs undergraduate researchers attach to their research experience}

Although the expectancy-value theory has been widely used in various fields to better understand the individuals' motivation to engage in specific tasks, "one component of this model, cost, has been largely ignored in empirical research" (Flake et al., 2015, p. 232). Understanding students' perceptions on what they have to give up to engage in a task or how much effort they anticipate to complete the task help researchers and educators better understand the students' motivation to engage in and pursue certain tasks (Cooper et al., 2019; Gin et al., 2018; Henry et al., 2019; Wigfield \& Cambria, 2010). Considering the costs, only some of the participants associated a cost to their research experience, and some of them associated more than one cost.

Students, especially in their early years in college, may not be aware of the STEM-related activities they can engage in, may not know how to access them, or may feel incompetent (Kuh, 2008). Institutions should seek ways to reach out to undergraduate students, increase their awareness and motivation to engage in STEM-related activities, as well as implement cost reduction interventions. UR programs or SUSTAIN-like projects may help provide opportunities for undergraduate students to participate in research projects. For instance, one of the participants indicated she would be unaware of undergraduate research, would not be motivated to participate, or would feel unqualified if the SUSTAIN project did not provide her the opportunity to participate in such research.

If it was not for SUSTAIN, I definitely would not have gone and been an undergraduate researcher here because I would not think I would have the time or I would not think I knew what I was doing or thought you would have to be a genius to be in there and stuff. But working there for the last two years has been great, and I have learned a lot of things. Not only academically but socially and within the STEM field that I would not have in a biology lecture or chemistry lecture.

Students' beliefs about their expectations of the task and how much time and effort they need to spend to be successful in that task may influence their motivation to pursue engaging in the task (Wigfield \& Cambria, 2010). Students usually come to college with unrealistic science and scientist images. Previous studies pointed out students' high expectations about the STEM field (Ball, Huang, Cotten, \& Rikard, 2017; Linnenbrink-Garcia et al., 2018), which may be related to stereotypical images of science and scientists. Explicit communication of the nature of science may help students set realistic 
expectations for their research experience and may increase our understanding of their selection behaviors and their engagement level with research. Also, knowing students' expectations and perceptions about the effort costs they associate with research may help design and develop effective research programs (Henry et al., 2019).

Engaging in research requires a time commitment. Some of the participants did not anticipate the time and amount of work scientists devote to their research. This is a learning experience and may differ in each research setting, and usually is not easy to foresee unless seeing the approximate daily work needs to be done to conduct the research. Providing an early research experience to college students may give them an idea about the lifetime of a research project and the amount of time and work needed to engage in the tasks (Kuh, 2008). Participants of this study were a selected group of low-income students. Even though the SUSTAIN project provided financial support to project participants, some of them still felt the need to work in external job(s) to support their financial needs. Therefore, a few participants commented on the indirect financial burden of engaging in research as it was hard for them to find part-time jobs while trying to engage in research for several hours a week. To decrease the financial burden, and give students the feeling of professionals, UR programs, institutions, and research centers should seek financial support for undergraduate researchers.

Another cost that participants associated with their research experience were the psychological and emotional costs, which were described as individuals' concerns and/or emotional consequences of failure. Only a few participants commented on the psychological cost of their research experience. Most of the participants indicated their and their mentors' awareness that they are first year and sophomore undergraduate students whose content knowledge and laboratory skills are limited. Research experience of early year undergraduate researchers may be improved by setting clear expectations of the laboratory experience for both students and mentors such as the amount of time and work expected, the extent of the teaching and learning experience, and the structure of the laboratory and members to decrease the psychological or emotional cost of engaging in research (Gin et al., 2018; Henry et al., 2019).

Opportunity cost, on the other hand, was the highest mentioned cost among the participants. Mostly participants with two semesters or less research experience commented on the opportunity cost of engaging in research and expressed the loss of valued alternatives. Conversely, as expected, participants who had three semesters or more research experience expressed that their research experience did not make them feel like they are missing other valued tasks. Future research may investigate which aspects of the research experience made students feel the highest opportunity costs and what can be done to reduce the costs of engaging in undergraduate research.

\section{Limitations and future directions}

This study has several limitations. Like other qualitative studies, the findings of this study cannot be generalized to a population because of the limited sample size and utilization of convenient sampling (Maxwell, 2013). While the sample size was sufficient to explore the research questions of this study, it was not large enough to reveal if there are significant differences within the population of early year undergraduate researchers. The study was also limited to a selected group of highachieving low-income undergraduate students in a private research university. There may be differences with different student groups and at different types of institutions, but this study cannot predict these differences. Moreover, the participants were motivated enough to apply to the SUSTAIN project, a comprehensive support program where they knew they would get a research experience, which further limits the generalizability of this study. Another limitation is that being paired with a mentor (who signed up to engage in this program) does not reflect the typical undergraduate research experience. It is likely, therefore, that the students may perceive more value in their research than a typical undergraduate researcher. The study is also limited by data collection tools. Interview protocols and progress reports were structured to let participants express their experiences, drivers, and barriers associated with their research experience. This method may have hindered the possibility of promoting to explain different types of value or costs. The data also limits the findings to link the manifestation of motivations or changes in motivational states to specific activities. Future research may provide a deeper descriptive analysis of what types of activities/tasks within a research experience are linked to various kinds of values and student explanations for why the experience linked to change in that value. Finally, the data analysis of the study is limited to one researcher. The researcher took various methodological actions to assure the reliability of the findings. Further research may include multiple researchers in the data analysis process to provide an inter-rater reliability check.

The findings of this study contribute to the current literature pointing out that a motivational approach may be useful for understanding early year undergraduate researchers' engagement with research. As perceived cost is the least studied in the EVT framework (Flake et al., 2015; Wigfield \& Cambria, 2010), this study contributes 
to cost values within college students, particularly about early year undergraduate researchers. The findings of this study can form the base for future work on values and costs in undergraduate research experiences. Future studies may focus on the motivational factors of early year undergraduate researchers by extending the population or in-depth exploration of subpopulations within early year undergraduate researchers. Further research may also focus on the evaluation and improvement of existing UR programs. Overall, the findings of this study may help the educators and the researchers to identify possible pathways for future studies to find ways to increase the value and decrease the costs students face during their research experience.

\section{Conclusion}

This study focused on the motivational factors to better understand early year undergraduate researchers' engagement with research (Eccles \& Wigfield, 2002). The association of task values and STEM persistence is highly addressed in the literature, but task values on STEMrelated interventions, such as UR, is little studied (Linnenbrink-Garcia et al., 2018). Therefore, this study aimed to fill this gap and focused on how much and in what ways early year undergraduate researchers value their research experience and what kinds of costs do they associate with it. The vast majority of the participants revealed that their primary motivation to engage in research was influenced by their personal interest in research. The second motivational factor was the utility value indicating that participants found their experience useful. The attainment value was the lowest commented motivational factor implying only some of the participants commented on the personal importance of research or how being a researcher fits with their identity. Considering the cost participants associated with their research experience, only some of the participants associated a cost to their research experience, and some of them associated more than one cost. The costs faced by participants varied by their gender, race/ethnicity, or the amount of their research experience. Overall, the findings of this study may help the educators and the researchers to identify possible pathways for future studies to find ways to increase the value and decrease the costs students face during their research experience.

\section{Abbreviations}

STEM: Science, technology, engineering, and mathematics;

UR: Undergraduate research

\section{Acknowledgements}

This study would not have been possible without SUSTAIN Scholars who participated in the project and shared their stories. Their honesty and willingness to reflect on their personal experiences were greatly appreciated.

\section{Authors' contributions}

The authors worked together on the research design and the draft of the manuscript. The first author generated the research questions and conducted the analyses. All the authors approved the final manuscript for submission. Please address correspondence to the first author.

\section{Funding}

This study is based upon work supported by the National Science Foundation under Grant No. 1644148. Any opinions, findings, and conclusions or recommendations expressed in these materials are those of the authors and do not necessarily reflect the views of the National Science Foundation.

\section{Availability of data and materials}

The data used in the current study are available from the corresponding author upon request.

\section{Competing interests}

The authors declared no potential conflicts of interest for the research, authorship, and/or publication of this article.

\section{Author details}

${ }^{1}$ Department of Mathematics and Science Education, Bogazici University, Istanbul, Turkey. 'Department of Science Teaching, Syracuse University, Syracuse, NY 13244, USA.

Received: 30 December 2019 Accepted: 7 September 2020

Published online: 26 October 2020

\section{References}

Adedokun, O. A., Bessenbacher, A. B., Parker, L. C., Kirkham, L. L., \& Burgess, W. D. (2013). Research skills and STEM undergraduate research students' aspirations for research careers: Mediating effects of research self-efficacy. Journal of Research in Science Teaching, 50(8), 940-951 https://doi.org/10.1002/tea.21102.

Appianing, J., \& Van Eck, R. N. (2018). Development and validation of the ValueExpectancy STEM Assessment Scale for students in higher education. International Journal of STEM Education, 5(1), 24 https://doi.org/10.1186/ s40594-018-0121-8.

Ball, C., Huang, K. T., Cotten, S. R., \& Rikard, R. V. (2017). Pressurizing the STEM pipeline: An expectancy-value theory analysis of youths' STEM attitudes. Journal of Science Education and Technology, 26(4), 372-382 https://doi.org/ 10.1007/s10956-017-9685-1.

Battle, A., \& Wigfield, A. (2003). College women's value orientations toward family, career, and graduate school. Journal of Vocational Behavior, 62(1), 56-75. https://doi.org/10.1016/S0001-8791(02)00037-4.

Bowman, N. A., \& Holmes, J. M. (2018). Getting off to a good start? First-year undergraduate research experiences and student outcomes. Higher Education, 76(1), 17-33 https://doi.org/10.1007/s10734-017-0191-4.

Buckley, J. A. (2010). Undergraduate research experiences: What students expect, what they do, and how they benefit. Indiana University: ProQuest Dissertations Publishing

Canning, E. A., Harackiewicz, J. M., Priniski, S. J., Hecht, C. A., Tibbetts, Y., \& Hyde, J. S. (2018). Improving performance and retention in introductory biology with a utility-value intervention. Journal of Educational Psychology, 110(6), 834 https://doi.org/10.1037/edu0000244.

Carlone, H. B., \& Johnson, A. (2007). Understanding the science experiences of successful women of color: Science identity as an analytic lens. Journal of Research in Science Teaching, 44(8), 1187-1218 https://doi.org/10.1002/tea.20237.

Ceyhan, G. D., \& Tillotson, J. W. (2020). Mentoring structures and the types of support provided to early-year undergraduate researchers. CBE Life Sciences Education, 19(3), ar26 https://doi.org/10.1187/cbe.19-09-0183.

Ceyhan, G. D., Thompson, A. N., Sloane, J. D., Wiles, J. R., \& Tillotson, J. W. (2019). The socialization and retention of low-income college students: The impact of a wrap-around intervention. International Journal of Higher Education, 8(6), 249-261 https://doi.org/10.5430/ijhe.v8n6p249.

Chemers, M. M., Zurbriggen, E. L., Syed, M., Goza, B. K., \& Bearman, S. (2011). The role of efficacy and identity in science career commitment among underrepresented minority students. Journal of Social Issues, 67(3), 469-491 https://doi.org/10.1111/j.1540-4560.2011.01710.x.

Cooper, K. M., Ashley, M., \& Brownell, S. E. (2017). Using expectancy value theory as a framework to reduce student resistance to active learning: A proof of concept. Journal of Microbiology \& Biology Education, 18(2) https://doi.org/10. 1128/jmbe.v18i2.1289. 
Cooper, K. M., Gin, L. E., Akeeh, B., Clark, C. E., Hunter, J. S., Roderick, T. B., ... Scott, R. A. (2019). Factors that predict life sciences student persistence in undergraduate research experiences. PLoS One, 14(8) https://doi.org/10.1371/ journal.pone.0220186.

Creswell, J. W., \& Poth, C. N. (2016). Qualitative inquiry and research design: Choosing among five approaches. Thousand Oaks, California: Sage Publications.

Cromley, J. G., Perez, T., \& Kaplan, A. (2016). Undergraduate STEM achievement and retention: Cognitive, motivational, and institutional factors and solutions. Policy Insights From the Behavioral and Brain Sciences, 3(1), 4-11 https://doi. org/10.1177/2372732215622648.

Eccles, J. S. (1983). Expectancies, values, and academic behavior. In J. T. Spencer (Ed.), Achievement and achievement motivation, (pp. 75-146). San Francisco: W. H. Freeman.

Eccles, J. S. (1994). Understanding women's educational and occupational choices: Applying the Eccles et al. model of achievement-related choices. Psychology of Women Quarterly, 18(4), 585-609 https://doi.org/10.1111/j.14716402.1994.tb01049.x.

Eccles, J. (2009). Who am I and what am I going to do with my life? Personal and collective identities as motivators of action. Educational Psychologist, 44(2), 78-89 https://doi.org/10.1080/00461520902832368.

Eccles, J. S., \& Wigfield, A. (2002). Motivational beliefs, values, and goals. Annual Review of Psychology, 53(1), 109-132.

Feng, X., \& Behar-Horenstein, L. (2019). Maximizing NVivo utilities to analyze open-ended responses. The Qualitative Report, 24(3), 563-571 https:// nsuworks.nova.edu/tar/vol24/iss3/11.

Fereday, J., \& Muir-Cochrane, E. (2006). Demonstrating rigor using thematic analysis: A hybrid approach of inductive and deductive coding and theme development. International Journal of Qualitative Methods, 5(1), 80-92 https:// doi.org/10.1177/160940690600500107.

Flake, J. K., Barron, K. E., Hulleman, C., McCoach, B. D., \& Welsh, M. E. (2015). Measuring cost: The forgotten component of expectancy-value theory. Contemporary Educational Psychology, 41, 232-244 https://doi.org/10.1016/j. cedpsych.2015.03.002

Gardner, G. E., Forrester, J. H., Jeffrey, P. S., Ferzli, M., \& Shea, D. (2015). Authentic science research opportunities: How do undergraduate students begin integration into a science community of practice? Journal of College Science Teaching, 44(4), 61-65 https://doi.org/10.2505/4/jcst15_044_04_61.

Gin, L. E., Rowland, A. A., Steinwand, B., Bruno, J., \& Corwin, L. A. (2018). Students who fail to achieve predefined research goals may still experience many positive outcomes as a result of CURE participation. CBE Life Sciences Education, 17(4), ar57 https://doi.org/10.1187/cbe.18-03-0036.

Henry, M. A., Shorter, S., Charkoudian, L., Heemstra, J. M., \& Corwin, L. A. (2019). FAlL is not a four-letter word: A theoretical framework for exploring undergraduate students' approaches to academic challenge and responses to failure in stem learning environments. CBE Life Sciences Education, 18(1), ar11 https://doi.org/10.1187/cbe.18-06-0108.

Hernandez, P. R., Schultz, P., Estrada, M., Woodcock, A., \& Chance, R. C. (2013). Sustaining optimal motivation: A longitudinal analysis of interventions to broaden participation of underrepresented students in STEM. Journal of Educational Psychology, 105(1), 89 https://doi.org/10.1037/a0029691.

Hernandez, P. R., Woodcock, A., Estrada, M., \& Schultz, P. W. (2018). Undergraduate research experiences broaden diversity in the scientific workforce. BioScience., 68, 204-211 https://doi.org/10.1093/biosci/bix163.

Hunter, A. B. Laursen, S. L., \& Seymour, E. (2007). Becoming a scientist: The role of undergraduate research in students' cognitive, personal, and professional development. Science Education, 91(1), 36-74. https://doi.org/10.1002/sce.20173.

Korstjens, l., \& Moser, A. (2018). Series: Practical guidance to qualitative research. Part 4: Trustworthiness and publishing. The European Journal of General Practice, 24(1), 120-124 https://doi.org/10.1080/13814788.2017.1375092.

Kuh, G. (2008). High-impact educational practices: What they are, who has access to the, and why they matter. Washington, DC: Association of American Colleges and Universities.

Lent, R. W., Brown, S. D., \& Hackett, G. (1994). Toward a unifying social cognitive theory of career and academic interest, choice, and performance. Journal of Vocational Behavior, 45(1), 79-122 https://doi.org/10.1006/jvbe.1994.1027.

Lincoln, Y. S., \& Guba, E. G. (1985). Naturalistic inquiry. Newbury Park, California: Sage Publications.

Linnenbrink-Garcia, L., Perez, T., Barger, M. M., ... Schwartz-Bloom, R. (2018). Repairing the leaky pipeline: A motivationally supportive intervention to enhance persistence in undergraduate science pathways. Contemporany Educational Psychology, 53, 181-195 https://doi.org/10.1016/j.cedpsych.2018.03.001.

Lopatto, D. (2010). Undergraduate research as a high-impact student experience. Peer Review, 12(2), 27.

Mabrouk, P. A., \& Peters, K. (2000). Student perspectives on undergraduate research (UR)experiences in chemistry and biology. CUR Quarterly, 21(1), 25-33.

Maltese, A., Harsh, J., \& Jung, E. (2017). Evaluating undergraduate research experiences-development of a self-report tool. Education Sciences, 7(4), 87. https://doi.org/10.3390/educsci7040087.

Masson, A. L., Klop, T., \& Osseweijer, P. (2016). An analysis of the impact of student-scientist interaction in a technology design activity, using the expectancy-value model of achievement related choice. International Journal of Technology and Design Education, 26(1), 81-104 https://doi.org/10.1007/ s10798-014-9296-6.

Maxwell, J. A. (2013). Qualitative research design: An interactive approach. Thousand Oaks, California: SAGE Publications.

McGee, R., \& Keller, J. L. (2007). Identifying future scientists: Predicting persistence into research training. CBE Life Sciences Education, 6(4), 316-331 https://doi. org/10.1187/cbe.07-04-0020.

McGrath, C. A., Gipson, K., Pierrakos, O., Nagel, R., Pappas, J., \& Peterson, M. (2013). An evaluation of freshman engineering persistence using expectancy-value theory. In 2013 IEEE Frontiers in Education Conference (FIE), 1644-1650.

Meaders, C. L., Lane, A. K., Morozov, A. I., Shuman, J. K., Toth, E. S. Stains, M. Smith, M. K. (2020). Undergraduate student concerns in introductory STEM courses: What they are, how they change, and what influences them. Journal for STEM Education Research, 1-22 https://doi.org/10.1007/s41979-020-00031-1.

Mosyjowski, E. A., Daly, S. R., Peters, D. L., Skerlos, S. J., \& Baker, A. B. (2017). Engineering PhD returners and direct-pathway students: Comparing expectancy, value, and cost. Journal of Engineering Education, 106(4), 639-676 https://doi.org/10.1002/jee.20182.

National Academies of Sciences, Engineering, and Medicine. (2016). Supporting students' college success: Assessment of intrapersonal and interpersonal competencies. Board on testing and assessment, division of behavioral and social sciences and education. Washington, DC: The National Academies Press.

National Survey of Student Engagement (2018). About NSSE. Retrieved from http://nsse.indiana.edu/html/annual_results.cfm.

Patton, M. Q. (2002). Two decades of developments in qualitative inquiry: A personal, experiential perspective. Qualitative Social Work, 1(3), 261-283.

Perez, T., Cromley, J. G., \& Kaplan, A. (2014). The role of identity development, values, and costs in college STEM retention. Journal of Educational Psychology, 106(1), 315-329 https://doi.org/10.1037/a0034027.

Peters, D. L., \& Daly, S. R. (2013). Returning to graduate school: Expectations of success, values of the degree, and managing the costs. Journal of Engineering Education, 102(2), 244-268 https://doi.org/10.1002/jee.20012.

Provencher, A., \& Kassel, R. (2017). High-impact practices and sophomore retention: Examining the effects of selection bias. Journal of College Student Retention: Research, Theory \& Practice, 152 https://doi.org/10.1177/1521025117697728.

Robinson, K. A., Perez, T., Nuttall, A. K., Roseth, C. J., \& Linnenbrink-Garcia, L. (2018). From science student to scientist: Predictors and outcomes of heterogeneous science identity trajectories in college. Developmental Psychology, 54(10), 1977-1992 https://doi.org/10.1037/dev0000567.

Robnett, R. D., Chemers, M. M., \& Zurbriggen, E. L. (2015). Longitudinal associations among undergraduates' research experience, self-efficacy, and identity. Journal of Research in Science Teaching, 52(6), 847-867 https://doi. org/10.1002/tea.21221.

Russell, S. H., Hancock, M. P., \& McCullough, J. (2007). Benefits of undergraduate research experiences. Science, 316(5824), 548-549. https//doi.org/10.1126/ science.1140384.

Ryan, R. M., \& Deci, E. L. (2000). Intrinsic and extrinsic motivations: Classic definitions and new directions. Contemporary Educational Psychology, 25(1), 54-67 https://doi.org/10.1006/ceps.1999.1020.

Schreiner, L. A., \& Tobolowsky, B. F. (2018). The role of faculty in sophomore success. New Directions for Higher Education, 183, 59-70. https://doi.org/10. 1002/he.20293

Seymour, E. \& Hewitt, N. M. (1997). Talking about leaving: Why undergraduates leave the sciences (Vol. 12). Boulder, CO: Westview Press.

Seymour, E., Hunter, A. B., Laursen, S. L., \& DeAntoni, T. (2004). Establishing the benefits of research experiences for undergraduates in the sciences: First findings from a three-year study. Science Education, 88(4), 493-534 https:// doi.org/10.1002/sce.10131. 
Thiry, H., Laursen, S. L., \& Hunter, A. B. (2011). What experiences help students become scientists? A comparative study of research and other sources of personal and professional gains for STEM undergraduates. The Journal of Higher Education, 82(4), 357-388 https://doi.org/10.1080/00221546.2011.11777209.

Thiry, H., Weston, T. J., Laursen, S. L., \& Hunter, A. B. (2012). The benefits of multiyear research experiences: Differences in novice and experienced students reported gains from undergraduate research. CBE-Life Sciences Education, 11(3), 260-272. https://doi.org/10.1187/cbe. 11-11-0098.

Torsney, B. M., Lombardi, D., \& Ponnock, A. (2019). The role of values in preservice teachers' intent ions for professional engagement. Educational Psychology, 39(1), 19-37 https://doi.org/10.1080/01443410.2018.1504892.

Wenger, E. (1998). Communities of practice: Learning as a social system. Systems Thinker, 9(5), 2-3 https://doi.org/10.1177/135050840072002.

Wigfield, A., \& Cambria, J. (2010). Expectancy-value theory: Retrospective and prospective. In The decade ahead: Theoretical perspectives on motivation and achievement (pp. 35-70). Emerald Group Publishing Limited.

Wigfield, A., \& Eccles, J. S. (2000). Expectancy-value theory of achievement motivation. Contemporary Educational Psychology, 25(1), 68-81 https://doi. org/10.1006/ceps.1999.1015.

\section{Publisher's Note}

Springer Nature remains neutral with regard to jurisdictional claims in published maps and institutional affiliations.

\section{Submit your manuscript to a SpringerOpen ${ }^{\circ}$ journal and benefit from:}

- Convenient online submission

- Rigorous peer review

- Open access: articles freely available online

High visibility within the field

- Retaining the copyright to your article

Submit your next manuscript at $\boldsymbol{\nabla}$ springeropen.com 